\title{
Pola Asuh Orang Tua Sebagai Faktor Penentu Kualitas Pemenuhan Kebutuhan Dasar Personal Hygiene Anak Usia 6-12 Tahun
}

\author{
Umi Mardliyah ${ }^{1}$, Anafrin Yugistyowati², Veriani Aprilia ${ }^{2}$ \\ 1,2,3 Sekolah Tinggi IImu Kesehatan Alma Ata Yogyakarta \\ Jalan Ringroad Barat Daya No 1 Tamantirto, Kasihan, Bantul Yogyakarta
}

\begin{abstract}
Abstrak
Masalah kesehatan yang sering terjadi pada anak usia sekolah dasar (6-12 tahun) adalah penyakit yang berhubungan dengan kebersihan diri anak. Penelitian ini bertujuan untuk mengetahui hubungan pola asuh orang tua dengan kualitas pemenuhan kebutuhan dasar personal hygiene anak usia 6-12 tahun di SDN Asem Cilik Kulon Progo Yogyakarta. Jenis penelitian ini adalah observasional analitik dengan menggunakan rancangan penelitian cross sectional. Pengambilan sampel dengan teknik simple random sampling dan diperoleh sampel yaitu 86 siswa. Analisis menggunakan uji Kendal Tau $(\tau)$ menunjukkan ada hubungan antara pola asuh orang tua dengan kualitas pemenuhan kebutuhan dasar personal hygiene anak usia 6-12 tahun di SDN Asem Cilik Kulon Progo Yogyakarta $(p<0.05)$. Hasil penelitian ini memberikan masukan bagi pelayanan kesehatan untuk meningkatkan pendidikan kesehatan kepada masyarakat khususnya anak usia sekolah tentang personal hygiene terkait dengan pencegahan penyakit melalui program Usaha Kesehatan Sekolah (UKS).
\end{abstract}

Kata Kunci: Pola Asuh Orang Tua, Kualitas Pemenuhan Kebutuhan Dasar Personal Hygiene, dan Anak Usia 6-12 Tahun.

\section{Parenting Pattern as Determinant Factors of Quality the Fulfillment Basic Needs of Personal Hygiene in Children 6-12 Years Old}

\begin{abstract}
Health problems that often occur in children of primary school age (6-12 years) are diseases associated with personal hygiene of the children. This study aimed to determine the relationship of parenting pattern with quality fulfillment of basic personal hygiene needs of children aged 6-12 years in SDN Asem Little Kulon Progo Yogyakarta. This analytic observational used cross-sectional study design. Sampling was determined with simple random sampling technique and obtained 86 students as respondents. Analysis using test Kendal $\operatorname{Tau}(\tau)$ showed no association between parenting pattern with quality fulfillment of basic personal hygiene needs of children aged 6-12 years in SDN Asem Little Kulon Progo Yogyakarta $(p<0.05)$. The results provide input for health services to improve health education to the community, especially school-age children about personal hygiene associated with the prevention of disease through School Health Unit (UKS).
\end{abstract}

Info Artikel:

Artikel dikirim pada 04 Juni 2013

Artikel diterima pada 05 Juni 2013

\section{Pendahuluan}

Anak sebagai generasi penerus bangsa, pada dasarnya tidak akan tumbuh dan berkembang dengan sendirinya. Anak akan melalui suatu perjalanan untuk tumbuh dan berkembang. Pertumbuhan mempunyai dampak terhadap perubahan fisik anak; sedangkan perkembangan merupakan segala perubahan yang terjadi pada anak baik secara fisik, kognitif, emosi maupun psikososial. Untuk dapat berkembang dengan optimal, anak memerlukan dukungan yang kondusif dari orang tua. ${ }^{1}$

Terdapat tiga jenis pola asuh orang tua yaitu pola asuh otoriter, permisif, dan demokratis. Dampak pola pengasuhan orang tua akan berbeda terhadap 
anak. Melalui pengasuhan orang tua, terutama orang tua yang demokratis, anak diharapkan dapat mengembangkan kemandiriannya dengan baik. Pola pengasuhan demokratis sangat mendukung perkembangan kemandirian (healthy autonomy) pada anak; sedangkan dua gaya pengasuhan lainnya yaitu pola pengasuhan otoriter dan permisif bersifat negatif terhadap kemandirian anak. ${ }^{2}$

Tahap perkembangan anak usia sekolah merupakan masa untuk meletakkan landasan yang kokoh bagi terwujudnya anak yang berkualitas dimana kesehatan merupakan faktor penting yang menentukan sumber daya manusia. ${ }^{3}$ Dengan adanya perkembangan era globalisasi dan adanya transisi demografi dan epidemologi penyakit, maka masalah penyakit akibat perilaku dan perubahan gaya hidup yang berkaitan dengan perilaku dan sosial budaya cenderung akan semakin kompleks. ${ }^{4}$ Masalahmasalah kesehatan yang sering terjadi pada anak usia sekolah dasar adalah penyakit yang berhubungan dengan kebersihan diri anak dan lingkungan.seperti gosok gigi, kebiasaan cuci tangan dan kebersihan diri yang masih kurang. ${ }^{5}$

Hasil data Riset Kesehatan Dasar secara nasional menunjukkan perilaku hidup bersih dan sehat (PHBS) yang baik adalah sebesar 32,3\%, dengan proporsi PHBS tertinggi pada DKI Jakarta $(56,8 \%)$ dan terendah pada Papua $(16,4 \%)$. Sebagai gambaran terdapat 20 dari 33 provinsi yang memiliki PHBS baik di bawah proporsi nasional. Riset ini sekaligus menunjukkan bahwa proporsi PHBS di Yogyakarta di atas proporsi nasional $(54,5 \%)$ dan proporsi PHBS yang baik lebih tinggi di perkotaan $(41,5 \%)$ dibandingkan di pedesaan $(22,8 \%)^{6}$.

Persentase personal hygiene pada siswa Sekolah Dasar Negeri Jatinagor secara keseluruhan pelaksanaannya masih rendah. Dari 6 jenis personal hygiene, hanya personal hygiene mata saja yang presentasenya lebih dari setengah dari keseluruhan siswa yang memiliki mata yang hygiene; sedangkan untuk personal hygiene rambut, telinga, mulut dan gigi, kulit, serta kuku tangan dan kaki lebih dari setengah dari keseluruhan siswanya tidak hygiene ${ }^{7}$.

Berdasarkan penelitian sebelumnya dengan judul "Hubungan Antara Pola Asuh Orang Tua dengan Status Personal Hygiene pada Anak Retardasi Mental Ringan dan Sedang di SLB II Yogyakarta". Hasil penelitian menunjukkan bahwa terdapat hubungan yang signifikan antara pola asuh orang tua dengan status personal hygiene pada retardasi mental ringan dan sedang ${ }^{8}$.

Berdasarkan studi pendahuluan yang dilakukanpeneliti didapatkan bahwa rata-rata perilaku dan kualitas personal hygiene siswa masih kurang yaitu ketika makan dan setelah bermain tidak membiasakan cuci tangan, 2 siswa yang memiliki mata yang tidak hygiene, 4 siswa memiliki rambut yang tidak tersisir rapi, 6 siswa memiliki mulut dan gigi yang tidak hygiene, 3 siswa memiliki kulit yang kering dan 4 siswa memiliki kuku tangan dan kaki yang panjang dan kotor. Berdasarkan hasil wawancara juga didapatkan data bahwa orang tua siswa menerapkan pola pengasuhan yang berbeda-beda dalam mengasuh anaknya terutama dalam kualitas pemenuhan kebutuhan dasar personal hygiene.

\section{Metode Penelitian}

Jenis penelitian ini adalah observasional analitik dengan menggunakan rancangan penelitian cross sectional ${ }^{9 \& 10}$. Populasi dalam penelitian ini adalah anak usia 6-12 tahun di SDN Asem Cilik Kulon Progo Yogyakarta dan orang tuanya yang berjumlah 110 orang. Pengambilan sampel dengan teknik simple random sampling dan dihitung berdasarkan tabel Krejcie sehingga diperoleh sampel yaitu 86 siswa, dan respondennya adalah orang tua siswa ${ }^{11}$. Variabel bebas dalam penelitan ini adalah pola asuh orang tua. Variabel terikat adalah kualitas pemenuhan kebutuhan dasar personal hygiene anak usia 6-12 tahun. variabel peneitian dianalisis menggunakan program SPSS 16. Penelitian ini dianalisis menggunakan uji Kendal $\operatorname{Tau}(\tau) 9$.

\section{Hasil dan Pembahasan}

\section{Hasil}

1. Karakteristik responden dan Sampel

Distribusi frekuensi berdasarkan karakteristik responden berdasarkan jenis kelamin, umur, pendidikan terakhir, dan jumlah anak dapat dilihat pada Tabel 1.

Tabel 1 menunjukkan gambaran karakteristik responden (orang tua). Dari tabel tersebut sebagian besar berjenis kelamin perempuan yaitu 46 orang $(53,5 \%)$. Mayoritas berumur antara 20-40 tahun yaitu sebanyak 58 orang $(67,4 \%)$. Sebagian besar berpendidikan terakhir SD dan SMP yaitu sebanyak 33 orang $(47,7 \%)$.Dan berdasarkan jumlah anak, sebagian besar orang tua responden mempunyai 2 anak yaitu sebanyak 39 orang $(45,3 \%)$.

Distribusi frekuensi berdasarkan karakteristik sampel berdasarkan jenis kelamin dan umur anak dapat dilihat pada Tabel 2.

Tabel 2 menunjukkan bahwa sebagian besar sampel berjenis kelamin perempuan yaitu sebanyak 44 siswa $(51,2 \%)$. Mayoritas berumur 9 tahun yaitu 21 siswa $(24,4 \%)$. 
Tabel 1. Tabel Distribusi Frekuensi Berdasarkan Karakteristik Responden (Orang Tua) di SDN Asem Cilik Kulon Progo Yogyakarta

\begin{tabular}{|c|c|c|}
\hline Karakteristik Responden (Orang Tua) & $\mathbf{N}$ & $\%$ \\
\hline \multicolumn{3}{|l|}{ Jenis Kelamin } \\
\hline Laki-laki & 40 & 46,5 \\
\hline Perempuan & 46 & 53,5 \\
\hline Total & 86 & 100 \\
\hline \multicolumn{3}{|l|}{ Umur } \\
\hline $20-40$ & 58 & 67,4 \\
\hline $41-60$ & 25 & 29,1 \\
\hline $61-80$ & 3 & 3,5 \\
\hline Total & 86 & 100 \\
\hline \multicolumn{3}{|l|}{ Pendidikan Terakhir } \\
\hline$<\mathrm{SD}$ & 6 & 7,0 \\
\hline SD & 33 & 38,4 \\
\hline SMP & 33 & 38,4 \\
\hline SMA & 12 & 14,0 \\
\hline D3 & 1 & 1,2 \\
\hline S1 & 1 & 1,2 \\
\hline Total & 86 & 100 \\
\hline \multicolumn{3}{|l|}{ Jumlah Anak } \\
\hline 1 anak & 21 & 24,4 \\
\hline 2 anak & 39 & 45,3 \\
\hline 3 anak & 15 & 17,4 \\
\hline 4 anak & 5 & 5,8 \\
\hline 5 anak & 5 & 5,8 \\
\hline 9 anak & 1 & 1,2 \\
\hline Total & 86 & 100 \\
\hline
\end{tabular}

Sumber: Data Primer

Tabel 2. Tabel 2 Distribusi Frekuensi Berdasarkan Karakteristik Sampel (Siswa) di SDN Asem Cilik Kulon Progo Yogyakarta

\begin{tabular}{lcc}
\hline Karakteristik Sampel (Siswa) & $\mathbf{N}$ & $\%$ \\
\hline Jenis Kelamin & & \\
Laki-laki & 42 & 48,8 \\
Perempuan & 44 & 51,2 \\
Total & 86 & 100 \\
\hline Umur & & \\
6 tahun & 2 & 2,3 \\
7 tahun & 14 & 16,3 \\
8 tahun & 16 & 18,6 \\
9 tahun & 21 & 24,4 \\
10 tahun & 10 & 11,6 \\
11 tahun & 16 & 18,6 \\
12 tahun & 7 & 8,1 \\
\hline Total & $\mathbf{8 6}$ & $\mathbf{1 0 0}$ \\
\hline
\end{tabular}

Sumber: Data Primer

\section{Pola Asuh Orang Tua}

Gambaran pola asuh orang tua dalam penelitian ini disajikan dalam interpretasi hasil pada Tabel 3.

Tabel 3 menunjukkan bahwa pola asuh orang tua dalam penelitian ini sebagian besar pola asuh demokratis yaitu 69 orang tua $(80,2 \%)$.
Tabel 3. Tabel Distribusi Pola Asuh Orang Tua Siswa di SDN Asem Cilik Kulon Progo Yogyakarta

\begin{tabular}{lcc}
\hline Pola Asuh & N & \% \\
\hline Demokratis & 69 & 80,2 \\
Otoriter & 9 & 10,5 \\
Permisif & 8 & 9,3 \\
\hline Total & 86 & 100 \\
\hline
\end{tabular}

Sumber : Data Primer

3. Kualitas Pemenuhan Kebutuhan Dasar Personal Hygiene

Gambaran kualitas pemenuhan kebutuhan dasar personal hygiene anak usia -12 tahun di SDN Asem Cilik Kulon Progo Yogyakarta dalam penelitian ini disajikan dalam interpretasi hasil pada Tabel 4.

Tabel 4. Tabel Distribusi Kualitas Pemenuhan

Kebutuhan Dasar Personal Hygiene Anak Usia -12

Tahun di SDN Asem Cilik Kulon Progo Yogyakarta

\begin{tabular}{lcc}
\hline $\begin{array}{l}\text { Kualitas Pemenuhan Kebutuhan } \\
\text { Dasar Personal Hygiene }\end{array}$ & $\mathbf{N}$ & $\%$ \\
\hline Kurang & 6 & 7,0 \\
Cukup & 70 & 81,4 \\
Baik & 10 & 11,6 \\
\hline Total & 86 & 100 \\
\hline
\end{tabular}

Sumber: Data Primer

Tabel 4 menunjukkan distribusi kualitas pemenuhan kebutuhan dasar personal hygiene anak usia 6-12 tahun. dari tabel tersebut bahwa sebagian besar kualitas pemenuhan kebutuhan dasar personal hygiene anak di SDN Asem Cilik Kulon Progo Yogyakarta dalam kategori cukup yaitu sebanyak 70 orang $(81,4 \%)$.

4. Hubungan Antara Pola Asuh Orang Tua dengan Kualitas Pemenuhan Kebutuhan Dasar Personal Hygiene Anak Usia 6-12 Tahun di SDN Asem Cilik Kulon Progo Yogyakarta

Tabulasi silang dan hasil uji statistik hubungan antara pola asuh orang tua dengan kualitas pemenuhan kebutuhan dasar personal hygiene anak usia 6-12 tahun dapat dilihat pada Tabel 5 .

Tabel 5 menunjukkan bahwa pola asuh demokratis dengan kualitas pemenuhan kebutuhan dasar personal hygiene yang kurang yaitu 1 anak $(1,2 \%)$.

Pola asuh demokratis dengan kualitas pemenuhan kebutuhan dasar personal hygiene yang cukup yaitu 58 anak $(67,4 \%)$. Dan pola asuh demokratis dengan kualitas pemenuhan kebutuhan dasar personal hygiene yang baik yaitu 10 anak $(11,6$ $\%)$. Pola asuh otoriter dengan kualitas pemenuhan kebutuhan dasar personal hygiene yang kurang yaitu 
Tabel 5. Tabulasi Silang Antara Pola Asuh Orang Tua dengan Kualitas Pemenuhan Kebutuhan Dasar Personal Hygiene Anak Usia 6-12 Tahun di SDN Asem Cilik Kulon Progo Yogyakarta

\begin{tabular}{|c|c|c|c|c|c|c|c|c|c|c|}
\hline \multirow{3}{*}{ Pola Asuh } & \multicolumn{8}{|c|}{ Kualitas Pemenuhan Kebutuhan Dasar Personal Hygiene } & \multirow{3}{*}{ Kendal Tau } & \multirow{3}{*}{ P-Value } \\
\hline & \multicolumn{2}{|c|}{ Kurang } & \multicolumn{2}{|c|}{ Cukup } & \multicolumn{2}{|c|}{ Baik } & \multicolumn{2}{|c|}{ Total } & & \\
\hline & $\mathrm{N}$ & $\%$ & $\mathrm{~N}$ & $\%$ & $\mathrm{~N}$ & $\%$ & $\mathrm{~N}$ & $\%$ & & \\
\hline Demokratis & 1 & 1,2 & 58 & 67,4 & 10 & 11,6 & 69 & 80,2 & & \\
\hline Otoriter & 1 & 1,2 & 8 & 9,3 & 0 & 0,0 & 9 & 10,5 & 0,393 & 0,000 \\
\hline Permisif & 4 & 4,7 & 4 & 4,7 & 0 & 0,0 & 8 & 9,3 & & \\
\hline Total & 31 & 36 & 46 & 53,5 & 9 & 10,5 & 86 & 100 & & \\
\hline
\end{tabular}

Sumber: Data Primer

1 anak (1,2 \%). Pola asuh otoriter dengan kualitas pemenuhan kebutuhan dasar personal hygiene yang cukup yaitu 8 anak (9,3\%). Dan pola asuh otoriter dengan kualitas pemenuhan kebutuhan dasar personal hygiene yang baik yaitu 0 anak (0\%). Pola asuh permisif dengan kualitas pemenuhan kebutuhan dasar personal hygiene kurang yaitu 4 anak $(4,7$ $\%)$. Pola asuh permisif dengan kualitas pemenuhan kebutuhan dasar personal hygiene cukup yaitu 4 anak $(4,7 \%)$. Dan pola asuh permisif dengan kualitas pemenuhan kebutuhan dasar personal hygiene baik yaitu 0 anak (0\%)Nilai signifikansi ( $p$-value) adalah $0,000(<0,05)$ pada uji Kendal Tau. Hal ini berarti koefisien korelasi yang ditemukan adalah signifikan $\left(\mathrm{H}_{0}\right.$ ditolak). Jadi ada hubungan yang signifikan antara pola asuh orang tua dengan kualitas pemenuhan kebutuhan dasar personal hygiene anak usia 6-12 tahun di SDN Asem Cilik Kulon Progo Yogyakarta.

Nilai korelasi pada uji Kendal Tau sebesar 0,393 , artinya korelasi bersifat positif yang rendah karena belum mendekati 1 yaitu berada dalam interval koefisien 0,00-0,199. Jadi ada hubungan positif yang rendah antara pola asuh orang tua dengan kualitas pemenuhan kebutuhan dasar personal hygiene anak usia 6-12 tahun di SDN Asem Cilik Kulon Progo Yogyakarta.

\section{Pembahasan}

\section{Pola Asuh Orang Tua}

Data yang didapatkan sebagian besar responden yaitu sebanyak 46 orang $(53,5 \%)$ berjenis kelamin perempuan. Hal ini menunjukkan bahwa ibu cukup berperan dalam proses pengasuhan anak karena secara umum ayah berperan sebagai kepala keluarga dan bertugas untuk mencari nafkah serta memenuhi kebutuhan keluarga; sedangkan ibu berperan penting dalam mengurus anak dan aktivitas rumah tangga ${ }^{2}$.

Berdasarkan karakteristik usia responden diketahui sebagian besar berada pada rentang usia antara 20-40 tahun yaitu sebesar $(67,4 \%)$. Pada tahapan masa dewasa ini biasanya individu telah mencapai kematangan dalam berfikir dan bersikap, sehingga dapat mempengaruhi orang tua dalam mendidik dan mengasuh anak. Jika anak mendapat pengasuhan yang tepat dari orang tua maka anak akan mampu tumbuh dan berkembang secara maksimal. Misalnya mampu mempertahankan kualitas yang baik dalam pemenuhan kebutuhan dasar personal hygiene. usia merupakan salah satu faktor yang mempengaruhi orang tua untuk dapat menjalankan peran pengasuhan. Usia yang terlalu muda atau terlalu tua akan menyebabkan peran pengasuhan yang diberikan orang tua menjadi kurang optimal. Hal ini disebabkan dalam menjalankan peran pengasuhan secara optimal diperlukan kekuatan fisik dan psikososial dalam melakukannya ${ }^{9}$.

Dilihat dari karakteristik tingkat pendidikan orang tua dalam penelitian ini diketahui, mayoritas orang tua berpendidikan SD dan SMP yaitu sebesar $(47,7 \%)$. Tingkat pendidikan orang tua berpengaruh terhadap terbentuknya pola pikir yang terbuka terhadap hal baru. Orang tua dengan pendidikan SD dan SMP telah mempunyai pola pikir yang cukup sebagai hasil dari proses pendidikan formal yang dijalaninya sehingga mempengaruhi perilaku dalam pengasuhan anak. Pendidikan yang semakin tinggi mempengaruhi pengalaman orang tua dalam pengasuhan anak sehingga akan meningkatkan kesiapan orang tua untuk menjalankan peran dan tanggung jawabnya ${ }^{2}$.

Didapatkan data bahwa sebagaian besar responden memiliki jumlah anak 2 orang. Orang tua yang telah mempunyai pengalaman sebelumya dalam merawat anak akan lebih siap menjalankan peran pengasuhan. Selain itu, mereka akan lebih mampu mengamati tanda-tanda pertumbuhan dan perkembangan anak dengan baik ${ }^{12}$.

Hasil penelitian pada tabel 3 menunjukkan bahwa sebagian besar pola asuh yang diterapkan orang tua responden di SDN Asem Cilik Kulon Progo Yogyakarta adalah pola asuh demokratis yaitu sebanyak 69 orang $(80,2 \%)$, kemudian yang menerapkan pola asuh otoriter sebanyak 9 orang 
$(10,5 \%)$ dan menerapkan pola asuh permisif sebanyak 8 orang $(9,3 \%)$.

Pola asuh yang diterapkan responden orang tua di SDN Asem Cilik Kulon Progo Yogyakarta pada anak sebagian besar adalah pola asuh demokratis. Pola asuh ini sangat baik diterapkan pada anak. Hal ini sesuai dengan hasil penelitian sebelumnya, tercatat bahwa sebagian besar orang tua pada pola asuh demokratis membentuk anak dengan konsep diri positif; sedangkan pola asuh otoriter dan permisif membentuk karakter anak dengan konsep diri negatif 13. Orang tua dalam pola asuh demokratis bersikap rasional dimana mereka selalu mendasari tindakannya pada rasio atau pemikiran. Kontrol yang diterapkan orang tua kuat dan konsisten, namun disertai dengan dukungan, pengertian dan keamanan ${ }^{2}$.

Jenis pola asuh yang serupa yaitu pola asuh lemah lembut dan penuh cinta kasih. Berbuat lembut kepada anak bukan berarti harus menuruti semua permintaan anak. Orang tua terlebih dahulu memahami keinginan anak, kemudian dengan penuh kasih sayang mengarahkannya untuk mengerti batasan tentang apa yang benar dan apa yang salah ${ }^{14}$. Hal ini sesuai dengan firman Allah dalam Al-Qur'an:

"Maka disebabkan rahmat dari Allah-lah kamu berlaku lemah lembut terhadap mereka. Sekiranya kamu bersikap keras lagi berhati kasar, tentulah mereka menjauhkan diri dari sekelilingmu. Karena itu maafkanlah mereka, mohonkanlah ampun bagi mereka, dan bermusyawarahlah dengan mereka dalam urusan itu (QS. Al-Imran: 159).

Sebagian responden di SDN Asem Cilik Kulon Progo Yogyakarta juga menerapkan pola asuh otoriter dan permisif. Orang tua dalam pola asuh permisif memberi pengawasan yang lebih longgar, memberikan kesempatan pada anaknya untuk melakukan sesuatu tanpa pengawasan atau kontrol yang cukup darinya ${ }^{2}$.

Pola asuh otoriter merupakan pola asuh dimana orang tua cenderung menetapkan standar yang mutlak harus dituruti, seperti halnya memaksa, memerintah, menghukum dan biasanya bersamaan dengan ancaman-ancaman. Orang tua mencoba untuk mengontrol perilaku dan sikap anak melalui perintah yang tidak boleh dibantah ${ }^{2}$. Sebagian orang tua menganggap bahwa mengasuh anak yang baik adalah dengan cara-cara yang keras, berkatakata keras dan kasar. Namun cara ini justru dapat menimbulkan dendam pada diri anak ${ }^{14}$.

\section{Kualitas Pemenuhan Kebutuhan Dasar Personal Hygiene}

Hasil penelitian berdasarkan Tabel 2 menunjukkan bahwa sebagian besar anak di
SDN Asem Cilik Kulon Progo Yogyakarta adalah perempuan yaitu sebanyak 44 orang $(51,2 \%)$. Jenis kelamin merupakan salah satu faktor yang perlu diperhatikan dalam perbedaan kualitas pemenuhan kebutuhan dasar personal hygiene seseorang. Karena perbedaan ini diduga dapat disebabkan faktor-faktor lingkungan ${ }^{15}$.

Dilihat dari karakteristik umur anak dalam Tabel 2 diketahui mayoritas anak berumur 9 tahun yaitu sebanyak 21 orang (24,4\%) .Usia juga merupakan faktor yang selalu diperhatikan dalam perbedaan kualitas pemenuhan kebutuhan dasar personal hygiene seseorang ${ }^{15}$. pengetahuan tentang pentingnya hygiene dan implikasinya bagi kesehatan mempengaruhi praktik hygiene, karena pengetahuan yang baik dapat meningkatkan derajat kesehatan ${ }^{16}$.

Hasil penelitian dalam Tabel 4 menunjukkan bahwa sebagian besar kualitas pemenuhan kebutuhan dasar personal hygiene responden di SDN Asem Cilik Kulon Progo Yogyakarta dalam kategori cukup yaitu sebanyak 70 orang $(81,4 \%)$. Hasil ini dapat diartikan bahwa anak belum mempunyai kemampuan secara penuh untuk menjaga kebersihan diri (personal hygiene). Pemenuhan perawatan diri dipengaruhi oleh beberapa faktor lain, diantaranya budaya, nilai sosial pada individu atau keluarga, pengetahuan terhadap perawatan diri, serta persepsi terhadap perawatan diri 17\&18. Hal ini didukung dengan hasil penelitian yang menunjukkan bahwa persentase personal hygiene pada siswa Sekolah Dasar Negeri Jatinagor secara keseluruhan pelaksanaannya masih rendah ${ }^{7}$.

3. Hubungan Antara Pola Asuh Orang Tua dengan Kualitas Pemenuhan Kebutuhan Dasar Personal Hygiene

Hasil penelitian ini ditunjukkan pada Tabel 5 bahwa ada hubungan positif yang bersifat rendah dan signifikan antara pola asuh orang tua dengan kualitas pemenuhan kebutuhan dasar personal hygiene anak usia 6-12 tahun di SDN Asem Cilik Kulon Progo Yogyakarta. Didukung dari hasil analisis uji Kendal Tau diperoleh nilai Kendal Tau sebesar 0,393 dengan signifikansi ( $p$-value) adalah $0,000(<$ 0,05 ). Hasil ini dapat diartikan bahwa pola asuh orang tua memberikan kontribusi positif yang rendah dan signifikan terhadap kualitas pemenuhan kebutuhan dasar personal hygiene anak usia 6-12 tahun. Orang tua yang menerapkan pola asuh demokratis pada anak akan mendukung tercapainya kualitas pemenuhan kebutuhan dasar personal hygiene menjadi cukup.

Hasil penelitian pada Tabel 5 menunjukkan bahwa sebagian besar orang tua yang menerapkan pola asuh demokratis anaknya mempunyai kualitas 
pemenuhan kebutuhan dasar personal hygiene yang cukup yaitu sebesar 58 anak $(67,4 \%)$. Hal ini dapat dijelaskan bahwa orang tua dalam pola asuh ini bersikap rasional dimana mereka selalu mendasari tindakannya pada rasio atau pemikiran. Kontrol yang diterapkan orang tua kuat dan konsisten, namun disertai dengan dukungan, pengertian dan keamanan 2. Pola asuh ini akan menghasilkan karakteristik anak yang mandiri, dapat mengontrol diri, dan mempunyai hubungan baik dengan temannya ${ }^{19}$.

Hasil penelitian ini sesuai dengan penelitian sebelumnya yang didapatkan ada hubungan yang signifikan antara pola asuh orang tua dengan status personal hygiene pada anak retardasi mental ringan dan sedang di SLB Negeri II Yogyakarta 8. Hasil penelitian yang menunjukkan adanya hubungan yang bermakna antara pola asuh orang tua dengan kemandirian pada anak usia pra sekolah di TK Aisyiyah Mendungan Sukoharjo ${ }^{20}$. Dan hasil penelitian yang menunjukkan ada hubungan antara pola asuh orang tua dengan perkembangan anak di R.A Darussalam Desa Sumber Mulyo Jogoroto Jombang. Kesamaan hasil penelitian ini menunjukkan bahwa pola asuh orang tua mempunyai peran yang sangat penting dalam perkembangan anak termasuk dalam kemandirian anak, serta dalam pemenuhan kebutuhan dasar personal hygiene ${ }^{21}$.

\section{Simpulan dan Saran}

\section{Simpulan}

Berdasarkan analisis data dan pembahasan dapat disimpulkan bahwa:

1. Sebagian besar karakteristik responden di SDN Asem Cilik Kulon Progo Yogyakarta berjenis kelamin perempuan $(53,5 \%)$, berumur $20-40$ tahun $(67,4 \%)$, dengan pendidikan terakhir tamat SD dan SMP (38,4 \%), dan memiliki 2 anak (45,3 \%). Karakteristik anak usia 6-12 tahun di SDN Asem Cilik Kulon Progo Yogyakarta mayoritas berjenis kelamin perempuan $(51,2 \%)$ dan berumur 9 tahun $(24,4 \%)$.

2. Mayoritas pola asuh yang diterapkan orang tua pada anak usia 6-12 tahun di SDN Asem Cilik Kulon Progo Yogyakarta adalah pola asuh demokratis $(80,2 \%)$.

3. Mayoritas kualitas pemenuhan kebutuhan dasar personal hygiene anak usia 6-12 tahun di SDN Asem Cilik Kulon Progo Yogyakarta dalam kategori cukup $(81,4 \%)$.

4. Ada hubungan antara pola asuh orang tua dengan kualitas pemenuhan kebutuhan dasar personal hygiene anak usia 6-12 tahun di SDN Asem Cilik Kulon Progo.

\section{Saran}

Berdasarkan hasil penelitian dan kesimpulan di atas, maka peneliti mencoba untuk memberikan saran-saran kepada:

1. Bagi Ilmu Keperawatan

Penelitian ini diharapkan dapat digunakan sebagai bahan masukan dan kajian dalam mengembangkan ilmu pengetahuan dan evidence based practice (EBP) khususnya tentang kualitas pemenuhan kebutuhan dasar personal hygiene pada anak usia sekolah (6-12 tahun).

2. Bagi Anak Usia Sekolah

Hasil dari penelitian ini diharapkan dapat bermanfaat bagi anak usia 6-12 tahun yaitu dapat meningkatkan kualitas pemenuhan kebutuhan dasar personal hygiene dalam kehidupan sehari-hari melalui pengarahan dan bimbingan yang diberikan dari orang tua maupun guru di sekolah.

3. Bagi Institusi Pendidikan

Hasil penelitian ini dapat menjadi masukan bagi para guru untuk membantu mengembangkan personal hygiene anak SDN Asem Cilik Kulon Progo Yogyakarta dengan memberikan pengarahan kepada siswa untuk selalu menjaga kebersihan diri.

4. Bagi Pelayanan Kesehatan Puskesmas

Hasil penelitian ini dapat menjadi masukan bagi pelayanan kesehatan untuk meningkatkan pendidikan kesehatan kepada masyarakat khususnya anak usia sekolah tentang personal hygiene terkait dengan pencegahan penyakit melalui program Usaha Kesehatan Sekolah (UKS).

5. Bagi Peneliti

Hasil dari penelitian ini diharapkan dapat digunakan sebagai sumber informasi kesehatan khususnya tentang pola asuh orang tua dan kualitas pemenuhan kebutuhan dasar personal hygiene anak sekolah dan dapat juga digunakan sebagai bahan acuan untuk penelitian selanjutnya.

\section{Daftar Pustaka}

1. Mulyadi, S. 2004. Membantu Anak Balita Menggelola Amarahnya. Jakarta: Erlangga.

2. Wong, D.L., Marilyn, H.E., David, W., \& Patricia, S. 2009. Buku Ajar Keperawatan Pediatrik: Wong's Essential of Pediatric Nursing, edisi 6, volume 1. Jakarta: EGC.

3. Nuryanti, L. 2008. Psikologi Anak. Jakarta: Indeks.

4. Notoatmodjo, S. 2007. Promosi Kesehatan \& IImu Perilaku. Jakarta: Rineka Cipta. 
5. Suprajitno. 2004. Asuhan Keperawatan Keluarga. Jakata: EGC.

6. R.I. Departemen Kesehatan. 2013. Riset Kesehartan Dasar. Jakarta: Departemen Kesehatan R.I.

7. Nurjannah, A., Windy, R., \& Lita, N. 2012. Personal Hygiene Siswa Sekolah Dasar Negeri Jatinagor. Student E-Journals. 1(1): 1-14.

8. Dasilva, E.B.X., Sri, H., \& Sri, R. 2012. Association Between Rearing Pattern Of Parents and Personal Hygiene Status Of Children With Slight and Medium Mental Retardation At SLB Negeri II Yogyakarta.E-Journal Respati. 1-14.

9. Supartini, Y. 2004. Buku Ajar Konsep Dasar Keperawatan Anak. Jakarta: EGC.

10. Pramawaty, N., \& Elis, H. 2012. Hubungan Pola Asuh Orang Tua dengan Konsep Diri Anak Usia Sekolah. Jurnal Nursing Studies. 1(1): 87-92.
11. Istadi, I. 2008. Seri Psikologi Anak: Mendidik Anak dengan Cinta. Bekasi: Pustaka Inti.

12. Notoatmodjo, S. 2011. Kesehatan Masyarakat: IImu \& Seni. Jakarta: Rineka Cipta.

13. Hidayat, A.A. 2006. Pengantar Kebutuhan Dasar Manusia: Aplikasi Konsep \& Proses Keperawatan. Jakarta: Salemba Medika.

14. Hidayat, A.A. 2008. Kebutuhan Dasar Manusia. Jakarta: Salemba Medika.

15. Santrok, J.W. 2007. Perkembangan Anak, edisi kesebelas, jilid 2. Jakarta: Erlangga.

16. Suseno, D.D., \& Irdawati. 2012. Hubungan Antara Pola Asuh Orang Tua dengan Kemandirian Anak Usia Prasekolah di TK Aisyiyah Mendungan Sukoharjo. E-Journal Akbid. 3(1): 1-8.

17. Fatimah, L. 2012. Hubungan Pola Asuh Orang Tua dengan Perkembangan Anak di R.A Darussalam Desa Sumber Mulyo Jogoroto Jombang. E-Journal Unipdu. 1(2). 1-6. 